\title{
Relationship between biomechanical parameters of lower limb and velocity of arm strike during punch Gyaku Zuki performance in karate
}

\author{
DR .Mohamed Ahmed Zayed \\ DR . Mohamed Abdel-Rahman Aly \\ Faculty of Physical Education, Alexandria University, Alexandria, Egypt
}

\section{INTRODUCTION:}

Karate Games has gained growing popularity since the beginning of the organization of local and international competitions [1]. Is one of the important fighting sports, it is practiced by many people of all ages around the world, that requires a high level of fitness besides the technical and mental preparation, and it also requires physical fitness elements such as force and speed. Therefore, punch in karate should be performed with high speed and force [2-6]. In striking skills which are done with high speed, start from feet to leg, leg to trunk and finally the punch ends with high speed of arm technique [7,8]. Karate players perform skills as fast as possible to gain points in the competition, as the skill of punch Gyaku Zuki which does not require a long time. This skill is used more in karate matches, it represents $32.8 \%$ of attack skills, and $33.85 \%$ of counterattack skills $[3,9,10]$. Punch Gyaku-zuki, also known as the reverse punch, is a technique commonly used in karate kumite, a form of competitive fighting, starts with a lunge forward by the left or right leg to impact the ground then the reverse arm executes the punch $[11,12]$. Punch gyaku-zuki is used in most the katas and committee competitions. The aim of this skill in karate, is hitting the rival in a controlled distance in the least time[7, 9]. The performance of this type of skills, all body parts must be used harmoniously of force and speed lower limb and transport them to upper limb to reach the required speed, this leads to achieve high quality of physical fitness on dynamical use of the whole body to win in fighting matches [13]. It is a sport that engages both movements of upper and lower limbs, it is necessary to examine their biomechanical research about the relationship between arm strike and lower limb[6]. Several studies were used biomechanical or electromyographic analysis of Punch Gyaku Zuki skill of upper limb only [14-16]. In our literature no studies emphasized the relationship between lower and upper limb with Punch Gyaku Zuki performance in karate, this relationship was studied in boxing by Danai giovani et al., 2012; Cheraghi, 2014 and indicated to an inverse relationship between the force in the lower limb and arm velocity [17, 18]. Karate players perform punch Gyaku Zuki skill by front leg land impact with peak ground reaction force to get 
a quick strike to the inverse arm. Thus, it is important to study the relationship between biomechanical parameters of lower limb and velocity of arm strike during Punch Gyaku Zuki performance in karate to determine the effects lower limb parameters on the striking arm velocity [9, 18-20].

\section{Methods.}

\subsection{Participants}

Five males of high level karate players were participated in this study (age 25 \pm 1.58 years; Age Training19.60 \pm 1.14 years; body mass: $75.40 \pm .55 \mathrm{~kg}$; height: $177.40 \pm 3.64 \mathrm{~cm}$ ). They were athletes in Alexandria, Egypt, and participated in regional and national competitions; and they are members of a professional Egyptian team.

\subsection{Procedures}

A 15 min warm-up was allowed for each participant generally, as well as stretching exercises and familiarization trials. The speed instructions for skill performance were selected because it is similar to the competition requirements, where the player attempts to perform Gyaku Zuki skill as fast as possible, and the best four trials were selected to be analyzed. A total of 40 successful trials were recorded for each participant with 30 second rest between trials.

Time of peak impact ground reaction force of front leg (s), peak impact ground reaction force of front leg $(\mathrm{N})$ in the moment of peak ground reaction force of front leg was measured using force platform (Bertec 4060-10) like figure1.After the measurements procedure, results were extracted by using Software Bertec Digital Acquire 4.0.10.307 (Figure 2.).

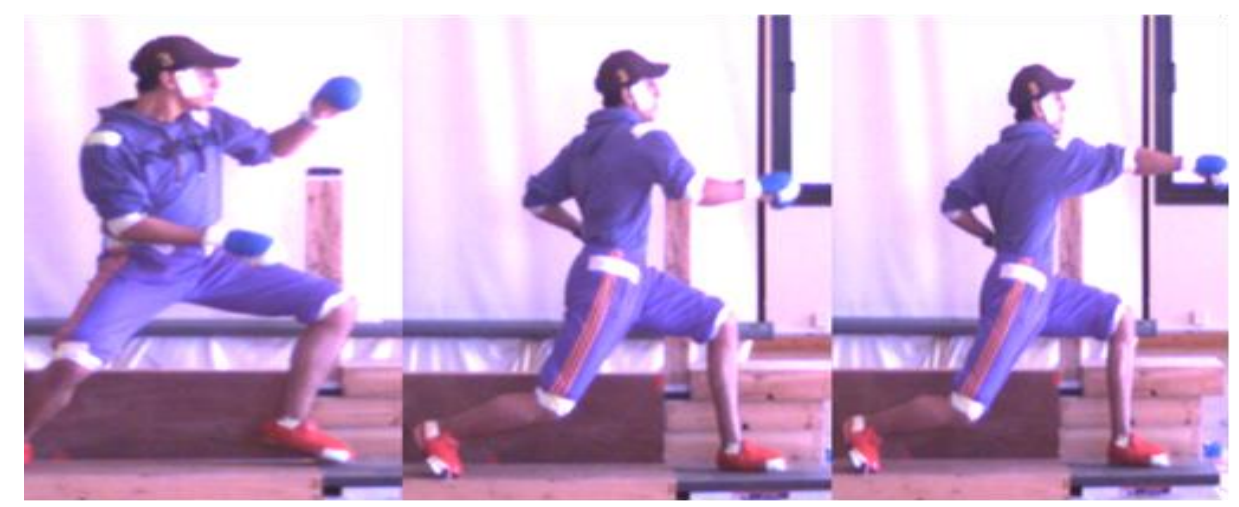

Figure 1 Representative time of peak impact ground reaction force of front leg $(S)$,peak impact ground reaction force of front leg $(N)$ was measured using force platform (Bertec 4060-10) 


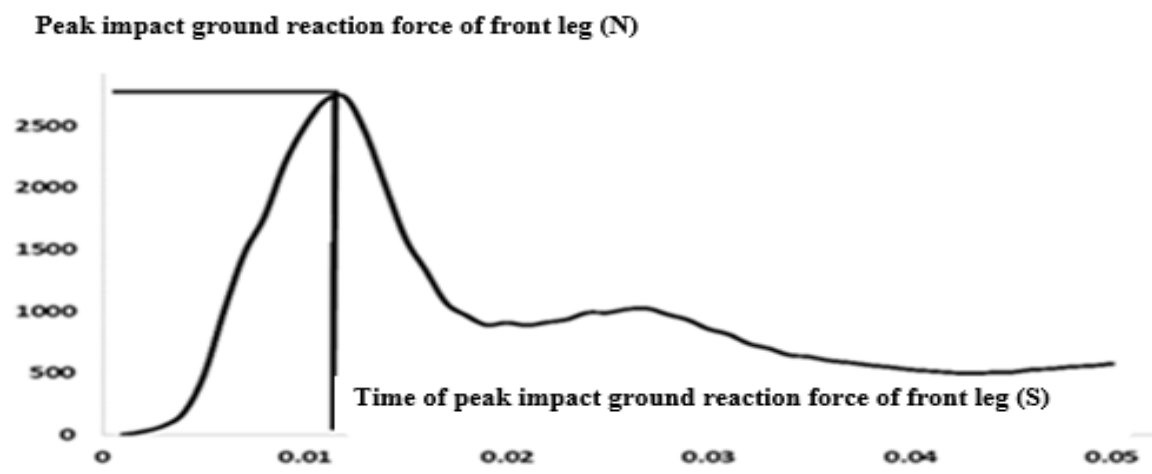

Figure 2 Representative time of peak impact ground reaction force of front leg $(S)$, peak impact ground reaction force of front leg ( $N)$ Curve.

Lower limb parameters as Distance lunge front leg (M), Time of front leg touch down force plate (S), Bake leg hip joint angle (deg), Bake leg Knee joint angle (deg), Bake leg ankle joint angle (deg), Front leg hip joint angle (deg), Front leg Knee joint angle (deg), Front leg ankle joint angle (deg), Velocity resultant center gravity bake of leg( $\mathrm{m} / \mathrm{s})$, Velocity resultant center gravity front of $\operatorname{leg}(\mathrm{m} / \mathrm{s})$, Velocity resultant center gravity of whole body $(\mathrm{m} / \mathrm{s})$, in the moment of peak ground reaction force of front leg, the upper limb parameter velocity resultant center gravity of arm strike $(\mathrm{m} / \mathrm{s})$ in the moment of hand punch, Fastec inline high-speed camera was used for capturing by $125 \mathrm{~Hz}$ frequency, and Video Point 2.5 was used for analysis (Figure 3).

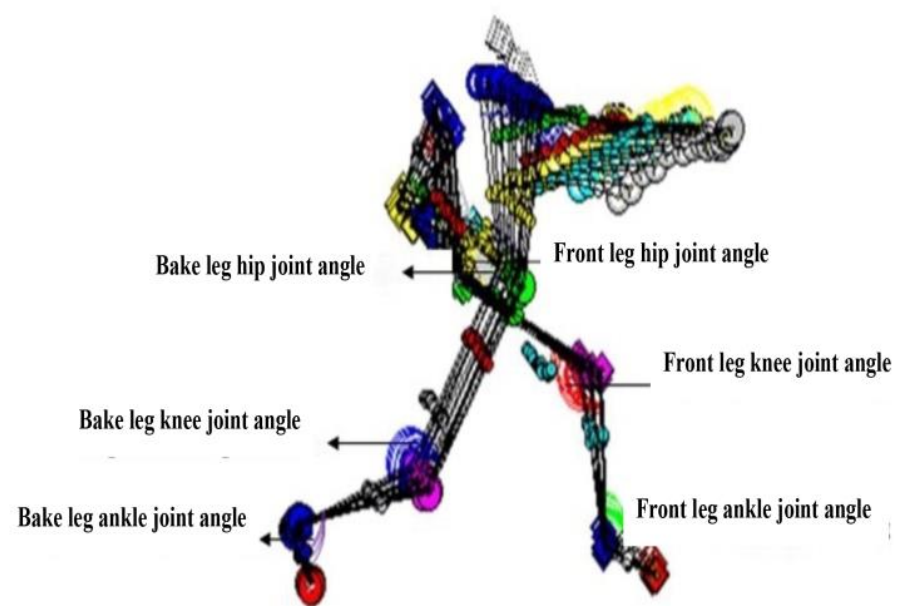

Figure 3 lower limb and velocity arm Strike was measured using High-Speed camera 125 frames/second (Fastec Inline model 250). Analysis video camera by Sport motion analysis (Video Point 2.5).

\subsection{Statistical Analysis}

Descriptive statistics and correlation was used to determine the relationship between 
biomechanical parameters of lower limb and Velocity of Arm strike during Gyaku Zuki performance in karate using IBM SPSS Statistics v21.

\section{Results.}

The descriptive and inferential statistics were used to analyze the data for statistical description of central parameters and distribution indices. The mean and standard deviation were calculated for parameters as Distance lunge front leg $(\mathrm{m})$, Time of front leg touch down force plate (s), Bake leg hip joint angle (deg), Bake leg Knee joint angle (deg), Bake leg ankle joint angle (deg), Front leg hip joint angle (deg), Front leg Knee joint angle (deg), Front leg ankle joint angle (deg), Velocity resultant center gravity bake of $\operatorname{leg}(\mathrm{m} / \mathrm{s})$, Velocity resultant center gravity front of $\operatorname{leg}(\mathrm{m} / \mathrm{s})$, Velocity resultant center gravity of whole body $(\mathrm{m} / \mathrm{s})$, Time of peak impact ground reaction force of front leg (s), peak impact ground reaction force of front leg $(\mathrm{N})$ Velocity resultant center gravity of arm strike $(\mathrm{m} / \mathrm{s})$. Analysis is provided in the form of mean \pm standard deviation in table1.

Table 1. Descriptive parameters (Minimum, Maximum, Mean, and Std. Deviation) of biomechanical parameters of lower limb and Velocity of arm strike during punch Gyaku Zuki performance in karate.

\begin{tabular}{|l|c|c|c|c|}
\hline \multicolumn{1}{|c|}{ Parameters } & Minimum & Maximum & Mean & $\begin{array}{c}\text { Std. } \\
\text { Deviation }\end{array}$ \\
\hline Distance lunge front leg (M) & 1.01 & 1.10 & 1.0575 & .02552 \\
\hline Time of front leg touch down force plate (s) & .13 & .18 & .1440 & .01314 \\
\hline Bake leg hip joint angle (deg) & 144.00 & 160.80 & 154.2450 & 4.68497 \\
\hline Bake leg Knee joint angle (deg) & 127.60 & 158.00 & 145.4150 & 9.64961 \\
\hline Bake leg ankle joint angle (deg) & 67.50 & 112.60 & 88.7410 & 12.06857 \\
\hline Front leg hip joint angle (deg) & 97.41 & 130.50 & 120.2755 & 8.87213 \\
\hline Front leg Knee joint angle (deg) & 125.30 & 144.20 & 137.5100 & 6.19812 \\
\hline Front leg ankle joint angle (deg) & 108.90 & 129.90 & 121.7850 & 6.44730 \\
\hline Velocity resultant center gravity bake of leg( m/s) & .25 & 1.54 & .9542 & .30269 \\
\hline Velocity resultant center gravity front of leg( $\mathrm{m} / \mathrm{s})$ & .75 & 2.64 & 1.4361 & .48942 \\
\hline Velocity resultant center gravity of whole body( m/s) & .86 & 1.49 & 1.2694 & .17658 \\
\hline Time of peak impact ground reaction force of front leg (s) & .01 & .02 & .0130 & .00237 \\
\hline peak impact ground reaction force of front leg (N) & 1932.39 & 3133.85 & 2576.0430 & 370.83169 \\
\hline Velocity resultant center gravity of arm strike (m/s) & .50 & 1.86 & 1.0471 & .32602 \\
\hline
\end{tabular}

The inverse relationship between parameters of velocity resultant center gravity of arm strike with Time of front leg touch down force plate was $-.491 *$ and with peak impact ground reaction force of front leg was $-.744^{*} *$. And positive relationship between parameters of velocity resultant center gravity of arm strike with peak impact ground reaction force time of front leg was .601** (Table 2). 
Table 2. Correlation parameters of Relationship between biomechanical parameters of lower

limb and Velocity of arm strike during punch Gyaku Zuki performance in karate

\begin{tabular}{|l|c|}
\hline \multicolumn{1}{|c|}{ Parameters } & $\begin{array}{c}\text { velocity resultant center } \\
\text { gravity of arm strike }\end{array}$ \\
\hline Distance lunge front leg (M) & -.168 \\
\hline Time of front leg touch down force plate (s) & $-.491^{*}$ \\
\hline Bake leg hip joint angle (deg) & .004 \\
\hline Bake leg Knee joint angle (deg) & .420 \\
\hline Bake leg ankle joint angle (deg) & -.343 \\
\hline Front leg hip joint angle (deg) & -.399 \\
\hline Front leg Knee joint angle (deg) & .136 \\
\hline Front leg ankle joint angle (deg) & -.400 \\
\hline Velocity resultant center gravity bake of leg( $\mathrm{m} / \mathrm{s})$ & .092 \\
\hline Velocity resultant center gravity front of leg( $\mathrm{m} / \mathrm{s})$ & .357 \\
\hline Velocity resultant center gravity of whole body( $\mathrm{m} / \mathrm{s})$ & .167 \\
\hline Time of peak impact ground reaction force of front leg $(\mathrm{s})$ & $.601^{* * *}$ \\
\hline peak impact ground reaction force of front leg $(\mathrm{N})$ & $-.744^{* *}$ \\
\hline
\end{tabular}

*. Correlation is significant at the 0.05 level (2-tailed).

**. Correlation is significant at the 0.01 level (2-tailed).

\section{Discussion}

The results indicate the inverse relationship between parameters of velocity resultant gravity center of arm strike with touch down on force plate time of front leg and with peak impact ground reaction force of front leg, so the fighter player start the movement forward by front leg with high speed, to reduce the distance with the other fighter player. This front leg speed leads to increase the striking arm velocity [16, 19]. The results also indicate that land impact with peak ground reaction force leads to decrease the striking arm velocity, for this reason karate players perform punch Gyaku Zuki skill wrongly by front leg land impact with peak ground reaction force to get a quick strike to the inverse arm, this is what the law of Newton confirms, for every action there is an equal and opposite reaction. But this action force comes with opposite reaction for arm strike velocity $[17,21]$. On the other hand, the aim of the front leg movement forward is not land impact with peak ground reaction force, but to reduce the fighting distance in less time as the striking arm velocity is due to trunk rotation velocity, but the reason of land impact is to stop the movement [7]. The results also indicate the positive relationship between impact time by front leg and arm strike velocity, so an increase in the impact time leads to the increase of the striking arm velocity. And this was due to the inverse correlation between impact force and it's time which is evident from the study results of Isaac Estevan and others 2011, these results show that the maximum impact force happen in a shorter execution impact time [22]. Finally, through the aforementioned, karate players can perform 
punch Gyaku Zuki skill of the highest velocity of the arm strike, by moving the front leg with minimum time and impact ground reaction force .

\section{CONCLUSION.}

The main finding in this study is that the front leg movement forward is not to land impact with peak ground reaction force, but to reduce the fighting distance in less time as the striking arm velocity is due to trunk rotation velocity, but the reason of land impact is to stop the movement forward. So, karate players can perform punch Gyaku Zuki skill of the highest velocity of the arm strike, by moving the front leg with minimum time and impact ground reaction force. And this relationship analysis between lower limb and velocity of arm strike is of major importance since it allows coaches and even players to identify the most appropriate to correct technique performance punch Gyaku Zuki Skill.

\section{References}

1. Chaabène, H., et al., Physiological Responses and Performance Analysis Difference between Official and Simulated Karate Combat Conditions. Asian Journal of Sports Medicine, 2014. 5: p. 21-29.

2. Randall G. Hassell, E.O., The Complete Idiot's Guide to Karate. 1 ed. 2000: Alpha.

3. Kerstin Witte, P.E., and Marion Lessau, Biomechanical measuring stations to solve practical problems in karate sport, seoul, korea, in International Society of Biomechanics in Sports 2008: Seoul, Korea. p. 14-18.

4. Čavala, M., et al., Karate Efficiency With The Function Of Developing Some Anthropological Features In 7th And 8th Grade Pupils In The Elementary School/ Efikasnost karatea u funkciji razvoja nekih antropoloških obilježja učenika 7. i 8. razreda osnovne škole. Croatian Journal of Education - Hrvatski časopis za odgoj i obrazovanje, 2015. 16(4): p. 911-933.

5. Pawlett, R., The Karate Handbook (Martial Arts). 2004, Kerswell, Parkham Ash, Devon, England: Silverdale Books.

6. Josefina Jukić, M.Č., The relations of specific motor ability and efficiency in karate of kadets. International Journal of Sport Psychology, 2013: p. 35-41.

7. Hariri, S., S. Nikokheslat, and A. Sarshin, Studying the Cinematographic Changes of with Impact and without Impact

Gyaku- Zuki Technique to Shootfist System among the Elite Male Karatekas. AENSI Journals, 2014: p. 34243429.

8. Urbinati, K.S., E. Scheeren, and P. Nohama, A new virtual instrument for estimating punch velocity in combat sports. Conf Proc IEEE Eng Med Biol Soc, 2013. p. 571-4.

9. Martin Hofmann, K.W., and Peter Emmermacher, Biomechanical Analysis of Fist Punch Gyaku-Zuki In Karate, in Scientific Proceedings of the XXVI International Conference on Biomechanics in Sports 2008: Seoul, Korea. p. 576-579.

10.Vidranski, T., F.M. , and a.J. Jukić, Differences in technical and tactical indicators of attacks and counterattacks in elite male karate fighters. Acta Kinesiologica 9, 2015. 9: p. 19-24.

11.Martin Hofmann, K.W., and Peter Emmermacher, Acceleration Course of Fist Push of Gyaku-Zuki, in 23International Conference on Biomechanics in Sports Beijing, China. 2005. p. 844-847.

12. Razali, R.A., Analysis of performance of the karate punch (gyaku-zuki), in 27 International Conference on Biomechanics in Sports. 2009: At Limerick, Ireland p. 1451.1528.

13. Wojciech Bajorek, W.C., Paweł Król,Marian Rzepko1,Grzegorz Sobota,Artur Litwiniuk, Assessment of postural stability in traditional karate contestants. Combat Sports and Martial Arts, 2011. 2: p. 23-29. 
14. Gianino, C., Physics of Karate. Kinematics analysis of karate techniques by a digital movie camera. LatinAmerican Journal of Physics Education 2010: p. 32-34.

15. Gabriela L. Ionete, et al., Experimental study on kinematics of gyaku-tsuki punch. Academic Journal, Annals of the University Dunarea de Jos of Galati: Fascicle XV:, 2011(1): p. p103-108.

16. VencesBrito, A.M., et al., Kinematic and electromyographic analyses of a karate punch. J Electromyogr Kinesiol, 2011. 21(6): p. 1023-9.

17. Danai giovani, a.p.t.n., Differences in Force-velocity Characteristics of Upper and Lower Limbs of Noncompetitive Male Boxers. International Journal of Exercise Science, 2012: p. 106-113.

18. Cheraghi, M., Kinematics of Straight Right Punch in Boxing. Annals of Applied Sport Science, 2014. 2: p. 39-50.

19. Hariri, S., et al., The Study of relationship between the speed at the GyakuZuki kick contact time and the displacement of contact plate in elite karatekas men. International Journal of Sport Studies. Vol, 2014.4 (12): p. 1513-1515.

20.Zink, A.J., et al., Peak power, ground reaction forces, and velocity during the squat exercise performed at different loads. J Strength Cond Res, 2006. 20(3): p. 658-64.

21. Knudson, D.V., Fundamentals of Biomechanics. 2003: Kluwer Academic/Plenum.

22. Estevan, I., et al., Impact force and time analysis influenced by execution distance in a roundhouse kick to the head in taekwondo. J Strength Cond Res, 2011. 25(10): p. 2851-6. 